\title{
Effect of ultrasonic irradiation on the coagulation and inactivation of Microcystis
}

\author{
Hong-Xing Shi, Jiu-Hui Qu, Hui-Juan Liu, Yin-Ling Mu, Kai-Tao Xiao \\ and Ling Wang
}

\begin{abstract}
The effectiveness of ultrasonic irradiation on coagulation and inactivity of algal cells was evaluated in the laboratory. Experiments were carried out under different conditions with or without ultrasound using polyaluminium hydroxychloride (PACl) as coagulant and Microcystis as test species. The results suggested that ultrasonic irradiation increased cells' inactivity and obviously improved the coagulation process of algal cells. An increased rate of coagulation and reduced dosage of $\mathrm{PACl}$ required to cause efficient flocculation for algae removal were observed in coagulation experiments with ultrasound irradiation. At the same time, compared with samples without irradiation, the characteristics of flocs were improved and the settling rate was increased greatly. A very short period of ultrasonic pretreatment with $40 \mathrm{~W}$ input power was enough to achieve substantial removal efficiency under the condition that there was no breakage in algal cells. The changes of growth curves for algal samples during the seven days' culturing suggested that ultrasound was effective for the inactivation of the test algae. The possible mechanisms for the enhanced effects on the coagulation and inactivity of Microcystis were that ultrasonic irradiation changed internal and external characteristics of algal cells, which co-promoted their immediate and accelerated coagulation and settlement.
\end{abstract}

Key words | algae, flocculation, inactivation, sedimentation, ultrasonic irradiation

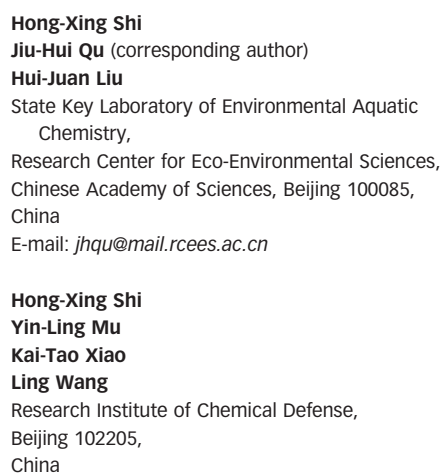

\section{$\overline{\text { INTRODUCTION }}$}

Many oxidants have been used to enhance the coagulation process, which is a main treatment process for algae removal in drinking water treatment. The effects of chlorine, ozone and chlorine dioxide on Scenedesmus sp. cultures have been studied (Sukenik et al. 1987). Algal cell viability and chlorophyll concentration decreased, but the concentration of dissolved organic substances increased with increasing applied oxidant concentration. Moreover, the negative effect of using chlorine and chlorine dioxide resulting from the formation of by-products is limiting the use of these chemicals as pre-oxidants. The ozonation of waters containing bromide may lead to the formation of bromate at a level suspected of being hazardous to health, which is a negative doi: 10.2166/aqua.2008.033 aspect for using ozone as a pre-oxidant (von Gunten 2003). It was also reported that pretreatment with permanganate $\left(\mathrm{KMnO}_{4}\right)$ and potassium ferrate $\left(\mathrm{K}_{2} \mathrm{FeO}_{4}\right)$ enhanced the coagulation process and specifically enhanced the removal of algae and other particulate matters in subsequent treatment steps (Ma et al. 1993, 1997, 2002).

Recently, power ultrasound has been noted as an effective technique for water treatment (Nagata et al. 1996; Hua \& Hoffmann 1997; Ince \& Belen 20or; Yim et al. 2003). During ultrasonic irradiation in aqueous solution, a shock wave and reactive free radicals are induced by violent collapse of cavitation bubbles. However, it seems likely that the mechanically destructive effect due to the shock wave 
is the predominant mechanism for the disinfection of microorganisms rather than the chemical effect of $\mathrm{OH}$ radicals (Furuta et al. 2004; Tsukamoto et al. 2004a). Moreover, recent studies suggest that the combined use of ultrasound and other techniques is more effective than the use of a single technique (Joyce et al. 2003; Lindermeir et al. 2003). In addition, ultrasonic irradiation alone for bluegreen algae (BGA) bloom control was also successfully studied (Lee et al. 200I, 2002).

Therefore, it is perhaps a good way to enhance coagulation by ultrasonic irradiation because of the effectiveness of ultrasound, the simplicity of the system and the absence of toxic by-products. First, ultrasonic irradiation can provide an effective method of directly attacking the gas vacuoles to make cells inactive and easy to remove by coagulation because of the actions of the unique cavitation bubbles. It is well established that the gas vacuoles in bluegreen algae principally function to regulate their position in the water column (Walsby ig68). Algal removal from water plants is difficult not only because of their small size and low specific gravity but also because of their floatability. So inhibition or destruction of the gas vacuoles might provide an effective alternative method for their control and be of benefit to coagulation in waterworks. Ultrasound not only collapsed gas vacuoles but may have also inflicted damage on the photosynthetic system of the BGA (Lee et al. 200I), which could also restrain further growth of algal cells in later processes of waterworks such as filtration and disinfection. Second, ultrasound has multiple effects on the morphology and surface characteristics of particles, creating substantial surface damage, increasing surface areas significantly and causing increased particle aggregation (Suslick et al. 1987). The surface of algal cells can be modified by ultrasonic irradiation, which makes the flocculation and sedimentation of cells easier. The efficiency of the flocculation process for inorganic particles and algal cells is influenced by the probability of two particles colliding with each other, as well as the ability of these particles to adhere after they were brought together by collision (Pieterse \& Cloot 1997). It is well known that ultrasound irradiation in the low frequency range $(20-150 \mathrm{kHz})$ has the effects of increased molecular vibration and greater levels of molecule collision, which can make the flocs become compact and easier to coagulate. Third, ultrasonic irradiation has the advantage that there is no need to add any chemicals to the water. So, it could provide an attractive option for algal removal because of the safety and convenience. Recently, ultrasonic irradiation has been studied especially for the disinfection process because of the simplicity of the system and the absence of toxic byproducts such as carcinogens formed during chlorination (Tsukamoto et al. 2004b; Shi \& Qu 2004).

In this study, the effects of ultrasonic irradiation on the coagulation and inactivity of algal cells were assessed using Microcystis as the test species, chosen for the experiments because of their frequent association with seasonal algal blooms. The specific objectives were: (1) to evaluate the effectiveness of ultrasonic irradiation on algae inactivity and removal by flocculation and sedimentation under suitable working conditions of ultrasonic irradiation, and (2) to discuss the possible mechanism of ultrasound enhanced efficiency.

\section{MATERIALS AND METHODS}

\section{Algae samples}

Two kinds of algae sample were used in the experiments. One was the field Microcystis, which was employed to research the effect of ultrasound on the coagulation and inactivation in most of the experiments of this work. The other kind of sample of algae was the pure Microcystis, which was used to research the possible mechanism of ultrasound effect on algae.

The field Microcystis was from a shallow lake located in Beijing, China. The water of this lake was a deep green colour indicating high algal concentration. Observation by microscopy showed that the lake water principally contained Microcystis. The raw water quality was listed as follows: turbidity $185 \mathrm{NTU}, \mathrm{pH} 9.3$, temperature $26^{\circ} \mathrm{C}$, dry weight concentration $228 \mathrm{mgl}^{-1}$.

The pure Microcystis was Microcystis aeruginosa which was obtained from the Culture Collection of Algae, Wuhan Institute of Hydrobiology of CAS, China, and was then grown in MA culture media. Cultures were maintained in an incubation chamber with controlled temperature and lighting. Fluorescent lamps were used as the light source 
with an automated $12 \mathrm{~h} / 12 \mathrm{~h}$ light/dark cycle. The light intensity during the light phase was 1,500 lux. Samples for experiments were prepared by inoculating exponentially growing cells into autoclaved media to give an initial concentration of about $2.6 \times 10^{9}$ cells $1^{-1}$ with $\mathrm{pH} 8.6$ at temperature $25^{\circ} \mathrm{C}$, whose optical density at $680 \mathrm{~nm}$ (OD 680) was about 0.077 when recorded on a UV/VIS spectrophotometer.

\section{Coagulant}

The coagulant was a commercial liquid product of polyaluminium chloride (PACl) from Tangshan Dongchang Industry Co. Ltd. Its concentration of PACl was $44.5 \mathrm{mgl}^{-1}$ (expressed as the weight of $\mathrm{Al}$ ). A pre-determined amount of PACl solution was directly added into samples without prior dilution.

\section{Coagulation and sedimentation}

The method reported by Strand et al. (200I) and Strand \& Varum (2003) was consulted in the coagulation of algal cells. All experiments were performed in a measuring cylinder with $250 \mathrm{ml}$ of algal suspension and $0.1-1.0 \mathrm{ml} \mathrm{PACl}$ solution at $25^{\circ} \mathrm{C}$. A corresponding blank was prepared by adding the same volume of $\mathrm{NaCl}$ as $\mathrm{PACl}$. With the coagulant being added, the algal suspension was stirred for $60 \mathrm{~s}$ at $200 \mathrm{rpm}$ (g value $900 \mathrm{~s}^{-1}$ ), it then began to react and settle for $30 \mathrm{~min}$. After being mixed round, one part of the sample was transported into the special bottles for turbidity measurement while the other part stayed in the cylinder for sedimentation.

A Hach $2100 \mathrm{~N}$ IS turbidimeter was used to give a direct reading of the turbidity of a sample in nephelometric turbidity units (NTU). The optical densities at $680 \mathrm{~nm}$ (OD 680) of the supernatants were measured on a UV/VIS spectrophotometer. Counting cells was performed in haemocytometers by microscope. The time of coagulation and sedimentation was recorded by a stopwatch.

The velocity of coagulation was assessed by the time between adding the coagulants and the occurrence of flocs. The effect of coagulation was expressed as the percentage decrease of initial turbidity. The settling velocity was determined by recording the change of the height of the interface level of algae flocs at different times because there was a clear level of interface of algae flocs during the settling. The final cumulate volume of flocs was recorded to compare the density of flocs in different conditions.

\section{Ultrasonic irradiation}

Samples were sonicated in a $250 \mathrm{ml}$ beaker using a cell disrupter (A SCIENTZ JY92-II D). The ultrasound frequency was $20 \mathrm{kHz}$. The sonication power was $0-400 \mathrm{~W}$ and the sonication period was $0-30 \mathrm{~min}$ with a $3 \mathrm{~s}$ off $/ 3 \mathrm{~s}$ on cycle. The temperature of the samples was maintained at $25^{\circ} \mathrm{C}$ in a water bath to prevent possible temperature effects. The titanium probe of the control unit was dipped in the algal suspension directly in ultrasonic operation. To assess the effect of ultrasonic irradiation, different samples were irradiated under different conditions.

In the coagulation and sedimentation experiments, the field Microcystis samples were treated with ultrasonic irradiation before adding coagulant into the samples. In the case of inactivation, pure Microcystis samples were treated by ultrasonic irradiation before they were incubated in an incubation chamber under the same culturing conditions.

\section{Inactivation examinations}

The change of growth curves was used to examine the effect of ultrasound on the inactivation and viability of algal cells. Growth curves of algae were measured by counting cells and measuring OD 680, which could give a proof of the ability of a cell to multiply. Cells treated with and without ultrasonic irradiation under various conditions were immediately moved back to the incubation chamber and cultured for 7 days under the same culturing conditions as usual.

The trypan blue dye exclusion assay was used to assess the possible damage of cell membrane by ultrasonic irradiation. Algal cells were treated by ultrasound at various exposure doses, then were immediately tested for cell viability by the trypan blue exclusion assay. Briefly, an equal volume of $0.4 \%(\mathrm{w} / \mathrm{v})$ trypan blue was added to the cell suspension after treatment, and mixed well. After 5 min incubation at room temperature, the number of cells excluding trypan blue (unstained) was counted using a haemocytometer to estimate the number of intact viable cells. The percentage viability $(\mathrm{Pv})$ was calculated as follow: 
$\mathrm{Pv}=$ Number of unstained cells $\times 100 /$ Total number of cells counted $(\%)$

\section{RESULTS AND DISCUSSION}

\section{The rate and effect of coagulation}

The rate of floc formation and the effect of coagulation with and without ultrasound are shown in Table 1. Comparative experiments were performed on the field Microcytis samples with or without ultrasonic irradiation. After adding $0.1 \mathrm{ml}$ $\mathrm{PACl}$ to $250 \mathrm{ml}$ raw lake water, the algal suspension was stirred for $60 \mathrm{~s}$ with $\mathrm{g}$ value $900 \mathrm{~s}^{-1}$. The time of the floc appearance in the cylinder was recorded.

As shown in Table 1, the flocs of the samples in the cylinder with ultrasound irradiation occurred earlier by $35 \mathrm{~s}$ than those without ultrasound treatment. That is to say, the coagulation rate of algae suspension with ultrasound was enhanced nearly three times compared with that without ultrasound. Table 1 also shows the difference in algal removal by coagulation with or without ultrasound. The removal of algae in samples treated with ultrasound reached $22.7 \%$ and $46.4 \%$ after coagulation for $5 \mathrm{~min}$ and $10 \mathrm{~min}$, respectively. However, that without ultrasound only reached $18.2 \%$ and $30.0 \%$ in the same time.

It was reported that ultrasound had multiple effects on the morphology and surface characteristics of inorganic solids, creating substantial surface damages, increasing surface areas significantly and causing increased particle aggregation (Suslick et al. I987). It was also reported that ultrasonic irradiation accelerated the agglutination reaction in the blood and antiserum mixture (Doubrovski \& Dvoretski 200o). In addition, micro-jets caused by acoustic cavitation enhanced mixing and could benefit the coagulation process (Kotyusov \& Nenctsov I996). Therefore, the

Table 1 | Comparison of coagulation without and with ultrasound

\begin{tabular}{lll} 
& without ultrasound & with ultrasound \\
\hline Time of floc occurring & $60 \mathrm{~s}$ & $25 \mathrm{~s}$ \\
NTU removal percentage after & $18.2 \%$ & $22.7 \%$ \\
$5 \mathrm{~min}$ & & \\
NTU removal percentage after & $30.0 \%$ & $46.4 \%$ \\
10 min & & \\
\hline
\end{tabular}

increased rate and effect of coagulation by ultrasound could be attributed to both accelerated dispersion of PACl and modification on interfaces of particles.

\section{Doses of coagulant in coagulation}

Figure 1 shows the difference in NTU removal by coagulation with and without ultrasonic irradiation with different $\mathrm{PACl}$ doses. The experiments were carried out under different doses of coagulants in the concentration range of $17.8-177.8 \mathrm{mgl}^{-1} \mathrm{PACl}$. In the case of ultrasonic irradiation, the power of ultrasound was $40 \mathrm{~W}$ and the exposure time was $30 \mathrm{~s}$. The algae samples were the field Microcystis.

As shown in Figure 1, although there was little difference found in the final removal percentage between coagulation with and without ultrasound, the interesting finding was that a mild reduction of $\mathrm{PACl}$ dosage was observed in the sample with ultrasonic irradiation. With ultrasound assisting, only $17.8 \mathrm{mgl}^{-1} \mathrm{PACl}$ was used to bring the removal efficiency to more than 98\%. On the other hand, without ultrasound assisting, $71.2 \mathrm{mgl}^{-1} \mathrm{PACl}$ was used, but the highest removal efficiency was less than $98 \%$. Thus, more than 3.5 times less $\mathrm{PACl}$ was used in coagulation with ultrasonic irradiation than without it.

This result was consistent with the work of Zhang et al. $(2006 b)$. However the dose of PACl in our work was much higher than that of theirs. The possible reason was that the Spirulina platensis was used for the study in their work. We knew that Spirulina platensis was different from Microcystis in many points such as figure and characteristics of coagulation (Pieterse \& Cloot I997).

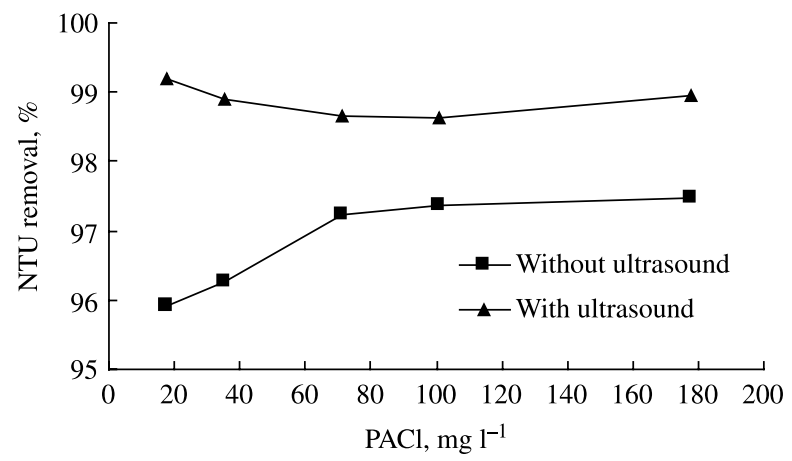

Figure 1 NTU removal by coagulation with different PACl doses. 
The reduction in $\mathrm{PACl}$ could be attributed to the differences in the electrophoresis and the coagulation between the intact and inactivated cell suspensions. The electrokinetic potential of the intact cells was higher compared with that of the inactivated ones, and the coagulation thresholds of the inactivated cells were lower compared with those of the intact ones (Ulberg \& Marochko 1999). So the inactivated cells with ultrasonic treatment needed a lower dose of PACl than normal cells.

\section{Settling rate of the formed flocs}

To obtain the settling profile, the sedimentation rates of algae after coagulation with and without ultrasonic irradiation are described in Figure 2. The experiments were done with the field Microcystis under the condition of $17.8 \mathrm{mg} \mathrm{l}^{-1} \mathrm{PACl}$. The ultrasonic condition was same as in the previous section.

As shown in Figure 2, the settling rate of the field Microcystis treated by ultrasound was higher than that without ultrasound during the 40 min sedimention time. In particular, in the first 10 min of settling, the floc assisted with ultrasonic irradiation maintained a stable settling rate of about $8 \mathrm{~mm} \mathrm{~min}^{-1}$ which was an increase of $54.5 \%$ over that without ultrasound assisting.

The increased rate of settling could be attributed to the increased density of flocs caused by ultrasonic irradiation.

\section{Strcture and density of the formed flocs}

Table 2 shows the differences between flocs made by coagulation with and without ultrasound. The experimental

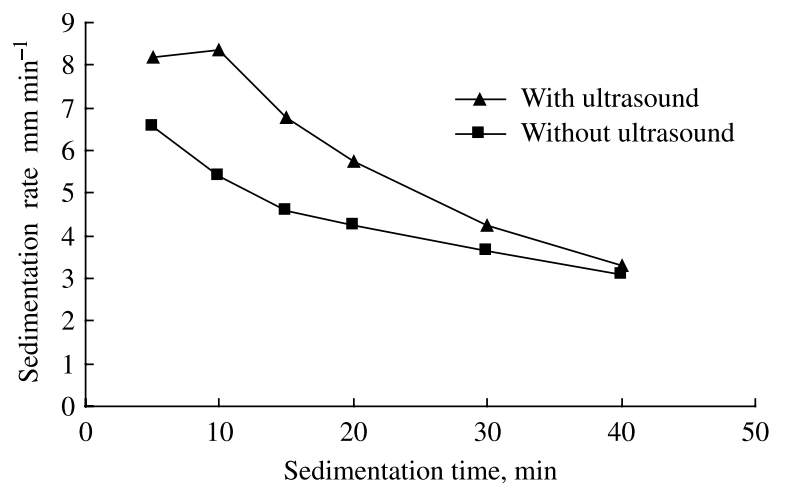

Figure 2 | Comparison of settling rates of the flocs of field Microcystis with and without ultrasound. condition was same as above. After settling for $24 \mathrm{~h}$, the final natural volume of flocs was recorded (Table 2) and the micrographs of two kinds of focs were observed (Figure 3).

As shown in Table 2 and Figure 3, the difference in floc appearance and in the ratio of final volume/total volume tells us that ultrasound made the structure of the focs more compact. The final density of flocs with ultrasound increased by 33\% compared with that of flocs without ultrasound.

The open structure of large flocs can give much lower sedimentation rates than for more compact flocs of the same mass (Gregory 1998). Therefore, perhaps the improved structure of flocs by ultrasound increased their settling rate.

In addition, Microcystis controlled their position in the water column by changing the specific gravity of their cells. It was reported that (Lee et al. 200I) short exposure (3s) to ultrasonic irradiation ( $120 \mathrm{~W}$ input power, $28 \mathrm{kHz}$ ) effectively settled naturally growing BGA suspension, and that sedimentation was caused by the disruption and collapse of gas vacuoles after ultrasonic exposure. The mechanism that led to increased specific gravity was not clear. One possibility was that ultrasonic irradiation results in the collapse of gas vesicles of the cells and renders the cells unable to float. Then the settling rate of flocs formed by cells increased.

\section{Effect of ultrasound on the cell interface}

The direct effect of ultrasound on the cell interface could be established by comparing Figure 4(a) and (b), which shows the changes of OD 680 and turbidity (NTU) of cell

Table 2 | Comparison of flocs without and with ultrasound

\begin{tabular}{lll} 
& Without ultrasound & with ultrasound \\
\hline Appearance of flocs & Incompact & Compact \\
Final volume/total volume & $39.1 \%$ & $29.5 \%$ \\
\hline
\end{tabular}
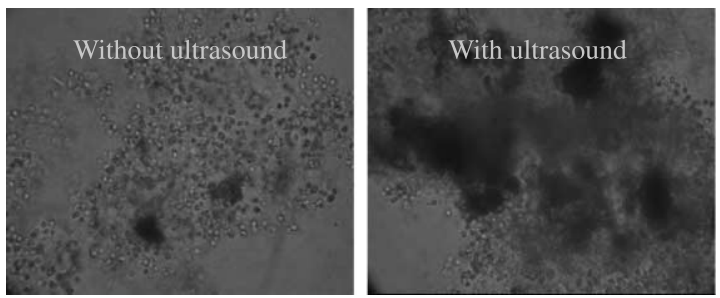

Figure 3 Comparison of flocs without and with ultrasound. 
suspension, respectively, with increasing exposure time to ultrasound. The pure Microcystis was employed in this experiment. The power of ultrasound was $40 \mathrm{~W}$ and the exposure time was $0-2.5 \mathrm{~min}$.

As shown in Figure 4(a), with the increased exposure time of cells to ultrasound, OD 680 decreased gradually. At the same time, the turbidity expressed as NTU fell suddenly after treatment by ultrasound and then kept at a stable level in cases with a higher irradiation dose (Figure 4(b)).

These results suggest that the cavitation caused by ultrasonic irradiation modified the surface of algal cells. It is well known that the OD 680 is a value of the intensity of transmission light through particles and that NTU is a value of the intensity of dispersion light by the surface of particles (Gao et al. 1999). Therefore, the difference between OD 680 and NTU is a kind of reflection of the differences in the changes of the particle surface. The experimental results showed that the interface characteristics of algal cells changed greatly but their bodies varied little after ultrasonic
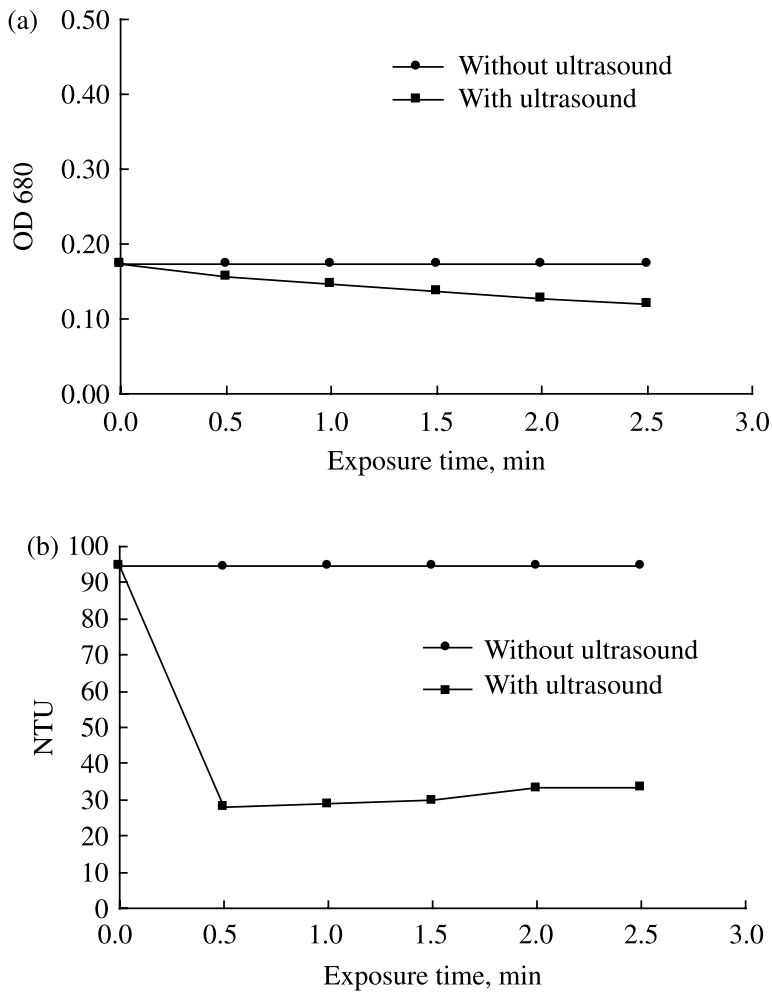

Figure 4 | (a) OD 680 under different exposure time to ultrasound; (b) NTU under different exposure time to ultrasound. irradiation. This gave direct proof of modification of the interface of algal cells by ultrasound.

\section{Effect of ultrasound on cell inactivation}

Changes in growth curves of two kinds of algae sample with and without treatment by ultrasound are shown in Figure 5 . The pure Microcystis was employed in this experiment. The power of ultrasound was $0 \mathrm{~W}$ or $40 \mathrm{~W}$ and the exposure time was $30 \mathrm{~s}$.

As shown in Figure 5, a significant reduction in cloning efficiency of cells was observed after treatments, which confirmed the sensitivity of algal cells to ultrasound. There was little change in cell density immediately after irradiation, but after 7-days' incubation under fluorescent light, there was significant difference in cell density between the samples with and without ultrasonic irradiation. The sample without irradiation grew normally during 7 days' culturing, but the sample treated with ultrasound at $40 \mathrm{~W}$ showed no growth, which suggested the inactivity of cells increased by ultrasound.

Ultrasonic irradiation could not only collapse gas vacuoles and precipitate BGA, but might have also inflicted damage on the photosynthetic system of the BGA (Lee et al. 200I; Zhang et al. 2006 a). For the same input power, a lower frequency was found to be more effective in decreasing the photosynthetic activity of BGA than a higher frequency (Lee et al. 200I). So in our experiments the lower irradiation frequency of ultrasound may have inflicted damage on the photosynthetic system of the Microcystis which limited their further growth after treatment.

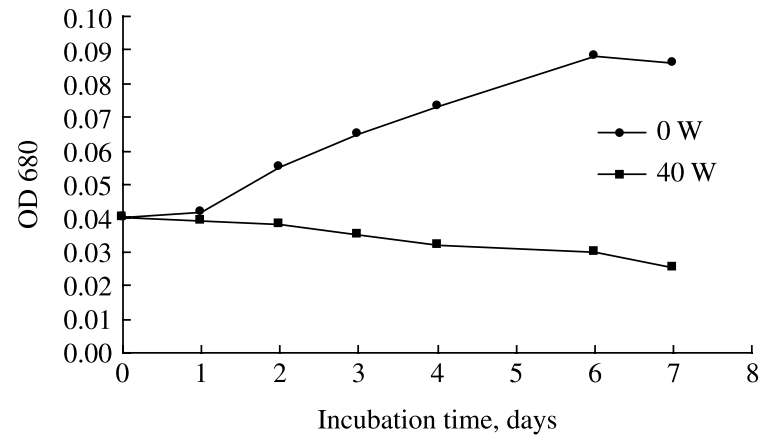

Figure 5 | Changes in growth curves of pure Microcystis. 


\section{Effect of ultrasound on the cell membrane}

The direct effect of ultrasound on the damage to the cell membrane is shown in Figure 6. The pure Microcystis was employed in this experiment. The power of ultrasound was $0-400 \mathrm{~W}$ and the exposure time was $30 \mathrm{~s}$. OD 680 and $\mathrm{Pv}$ were recorded after treatment with ultrasound.

As shown in Figure 6, both Pv and OD 680 were kept stable in the range of normal analysis error with treatment of ultrasound power less than $100 \mathrm{~W}$, but they dropped quickly when the power increased to more than $100 \mathrm{~W}$. The changes of $\mathrm{Pv}$ and $\mathrm{OD} 680$ with the input power of ultrasound suggested that less than $100 \mathrm{~W}$ ultrasound was safe for Microcystis because little cell destruction appeared at these intensities. However, ultrasound irradiation at $40 \mathrm{~W}$ could inactive cells, that is to say, the range of ultrasound power from $40 \mathrm{~W}$ to $100 \mathrm{~W}$ was suitable. In this range, Microcystis cells could be inactivated by the internal damage to the photosynthetic system, but could not be cracked by external damage to the cell membrane.

Therefore, the problem of the release of microcystins from broken cells was not relevant because the cells were not broken by less than $100 \mathrm{~W}$ ultrasound. This has also been supported by other reports. When cultivated epithelial lens cells were submitted to a $20 \mathrm{kHz}$ continuous ultrasonic irradiation, the destruction of the cells was observed only at relativity high intensity (Treton et al. 1977). It was also reported that even after $5 \mathrm{~min}$ of exposure to ultrasonic irradiation $(1,200 \mathrm{~W}$ input power, $28 \mathrm{kHz})$ the microcystin concentration in BGA suspensions did not increase (Lee et al. 200I).

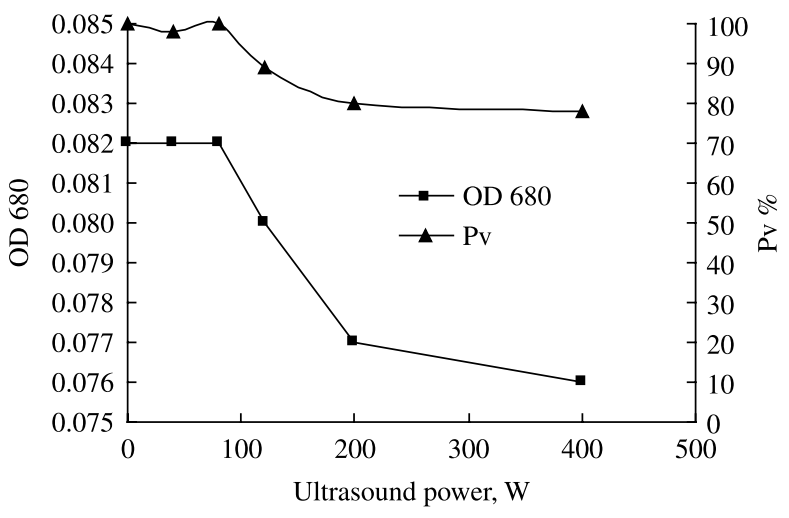

Figure 6 | Damage to cell membrane with different ultrasound power.

\section{CONCLUSION}

Laboratory studies using the field Microcystis and the pure Microcystis demonstrated that pretreatment with ultrasound obviously enhanced the coagulation process of algae. Microcystis treated suffered with ultrasonic irradiation could be removed more readily and rapidly by flocculation-sedimentation, the dosage of $\mathrm{PACl}$ was reduced, and the sedimentation rate of flocs was increased. Less than $100 \mathrm{~W}$ ultrasound was effective for the inactivation of the test algae while the cells were not broken.

Efficient removal of algae caused by ultrasound pretreatment and coagulation with $\mathrm{PACl}$ was suggested to be a consequence of several process mechanisms. The compact structure of flocs, the modification of the external interface of particles, and inactivation of cells brought about by ultrasonic irradiation co-promoted close adsorption between cells leading to their immediate and accelerated settlement.

\section{ACKNOWLEDGEMENTS}

The authors appreciate the generous financial support of National Science Fund for Distinguished Young Scholars (No. 50225824) and National Science Fund (No. 20677078).

\section{REFERENCES}

Doubrovski, V. A. \& Dvoretski, K. N. 2000 Ultrasonic wave action upon the red blood cell agglutination in vitro. Ultrasound Med. Biol. 26(4), 655-659.

Furuta, M., Yamaguchi, M., Tsukamoto, T., Yim, B., Stavarache, C. E., Hasiba, K. \& Maeda, Y. 2004 Inactivation of Escherichia coli by ultrasonic irradiation. Ultrason. Sonochem. 11(2), 57-60.

Gao, J., Zhao, F. \& Chen, X. I999 Laser application in turbidimetric measurement. Laser Technol. (Chinese) 23(4), 12-18.

Gregory, J. I998 The role of floc density in solid-liquid separation. Filtr. Separat., $367-371$.

Hua, I. \& Hoffmann, M. R. 1997 Optimization of ultrasonic irradiation as an advanced oxidation technology. Environ. Sci. Technol. 31, 2237-2243.

Ince, N. I. \& Belen, R. 200I Aqueous phase disinfection with power ultrasound: process kinetics and effect of solid catalysts. Environ. Sci. Technol. 35, 1885-1888.

Joyce, E., Mason, T. J., Phull, S. S. \& Lorimer, J. P. 2003 The development and evaluation of electrolysis in conjunction with 
power ultrasound for the disinfection of bacterial suspensions. Ultrason. Sonochem. 10(4-5), 231-234.

Kotyusov, A. \& Nenctsov, B. E. 1996 Induced coagulation of small particles under the action of sound. Acustica 82, 459-463.

Lee, T. J., Nakano, K. \& Matsumara, M. 20or Ultrasonic irradiation for blue-green algae bloom control. Environ. Technol. 22(4), $383-390$

Lee, T. J., Nakano, K. \& Matsumara, M. 2002 A novel strategy for cyanobacterial bloom control by ultrasonic irradiation. Water Sci. Technol. 46(6-7), 207-215.

Lindermeir, A., Horst, C. \& Hoffmann, U. 2003 Ultrasound assisted electrochemical oxidation of substituted toluenes. Ultrason. Sonochem. 10(4-5), 223-229.

Ma, J., Graham, N. \& Li, G. B. 1997 Effectiveness of permanganate preoxidation in enhancing the coagulation of surface watersLaboratory case studies. J. Wat. Suppl. Res. Technol.-AQUA 46, $1-11$.

Ma, J. \& Li, G. B. 1993 Laboratory and full-scale plant studies of permanganate oxidation as an aid to the coagulation. Water Sci. Technol. 27, 47-54.

Ma, J. \& Liu, W. 2002 Effectiveness and mechanism of potassium ferrate (VI) preoxidation for algae removal by coagulation. Water Res. 36, 871-878.

Nagata, Y., Hirai, K., Bandow, H. \& Maeda, Y. 1996 Decomposition of hydroxybenzoic and humic acids in water by ultrasonic irradiation. Environ. Sci. Technol. 30, 1133-1138.

Pieterse, A. J. H. \& Cloot, A. 1997 Algal cells and coagulation, flocculation and sedimentation process. Water Sci. Techol. 36(4), $111-118$.

Shi, H. X. \& Qu, J. H. 2004 Ultrasonic irradiation enhanced coagulation-sedimentation and inactivity of blue-green algae. The 12th International Symposium on River and Lake Environment, Wuhan, China, 1-11 November 2004.

Strand, S. P. \& Varum, K. M. 2003 Interactions between chitosans and bacterial suspensions: adsorption and flocculation. Colloid Surface B 27, 71-81.
Strand, S. P., Vandvik, M. S., Varum, K. M. \& Ostgaard, K. 200I Screening of chitosans and conditions for bacterial flocculation. Biomacromolecules 2(1), 126-133.

Sukenik, A., Teltch, B., Wachs, A. W., Shelef, G., Nir, I. \& Levanon, D. 1987 Effect of oxidants on microalgal coagulation. Water Res. 21(5), 533-539.

Suslick, K. S., Casadonte, D. J., Green, M. L. H. \& Thompson, M. E. I987 Effects of high intensity ultrasound on inorganic solids. Ultrasonics 25(1), 56-59.

Treton, J. A., Courtois, Y. \& Lang, J. 1977 Action of ultrasonic irradiation on the DNA of cultivated bovine epithelial lens cell. Biomedicine 27(8), 303-307.

Tsukamoto, I., Constantinoiu, E., Furuta, M., Nishimura, R. \& Maeda, Y. 2004a Inactivation effect of sonication and chlorination on Saccharomyces cerevisiae. Calorimetric analysis. Ultrason. Sonochem. 11(3-4), 167-172.

Tsukamoto, I., Yim, B., Stavarache, C. E., Furuta, M., Hashiba, K. \& Maeda, Y. $2004 b$ Inactivation of Saccharomyces cerevisiae by ultrasonic irradiation. Ultrason. Sonochem. 11, 61-65.

Ulberg, Z. R. \& Marochko, L. G. 1999 The electrophoretic properties and stability of the cell suspensions. Colloid Surface A 159, 513-518.

von Gunten, U. 2003 Ozonation of drinking water: Part II. disinfection and by-product formation in presence of bromide, iodide or chlorine. Water Res. 37(7), 1469-1487.

Walsby, A. E. 1968 An algae's buoyancy bags. New Sci. 40, $436-437$.

Yim, B., Yoo, Y. \& Maeda, Y. 2003 Sonolysis of alkylphenols in aqueous solution with $\mathrm{Fe}(\mathrm{II})$ and $\mathrm{Fe}(\mathrm{III})$. Chemosphere 50, $1015-1023$.

Zhang, G., Zhang, P., Liu, H. \& Wang, B. 2006a Ultrasonic damages on cyanobacterial photosynthesis. Ultrasonics Sonochem. 13(6), 501-505.

Zhang, G., Zhang, P., Wang, B., Wang, L. \& Wang, H. $2006 b$ Removal of algae by sonication-coagulation. J. Environ. Sci. Heal. A, 41(7), 1379-1390.

First received 1 March 2007; accepted in revised form 10 August 2007 